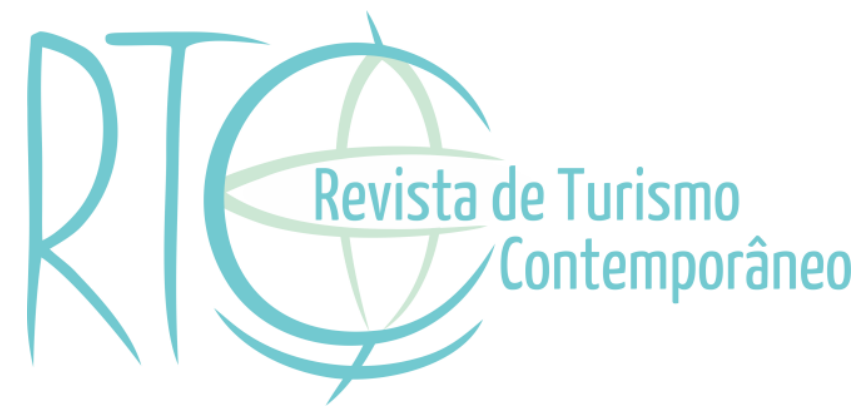

\title{
Precarização do trabalho no setor de eventos: um estudo inicial sobre os impactos para os trabalhadores e empresas
}

\author{
Precarious work in the events sector: a study about \\ impacts for workers and companies
}

Marcella de Oliveira Silva

Bacharel em Turismo pela Universidade Federal Rural do Rio de Janeiro - UFRRJ, Seropédica/RJ, Brasil

E-mail: marcellaoliveira@gmail.com

\section{Natasha Bantim}

Doutoranda em Planejamento Urbano e Regional pela Universidade Federal do Rio de Janeiro - UFRJ, Rio de Janeiro/RJ, Brasil

E-mail: natashabantim@id.uff.br

\section{Maria Angélica Maciel Costa}

Professora adjunta no Departamento de Administração e Turismo da Universidade Federal Rural do Rio de Janeiro - UFRRJ, Seropédica/RJ, Brasil

E-mail: mangelicamc@hotmail.com 


\section{RESUMO}

Esse trabalho tem como objetivo discutir a precarização nas relações de trabalho em um dos ramos mais relevantes do turismo: o setor de eventos. Apesar de ocupar posição econômica estratégica e proporcionar visibilidade dos destinos no mercado global, o setor se mantém, em grande parte, através de relações de trabalho terceirizadas, temporárias e informais. Essas relações são advindas do modelo financeiro internacional, de acumulação flexível do capital, onde o contrato de trabalho com todos os direitos e obrigações previamente definidos e inalterados ao longo de sua duração, vem sendo trocado por modelos menos rígidos, a partir da chamada 'reestruturação produtiva'. Para exemplificar essas relações, foi analisada uma empresa localizada no Rio de Janeiro (RJ), especializada em orientação de público em eventos e seus contratados. Verificou-se a percepção de clientes e funcionários sobre os serviços prestados e a percepção dos trabalhadores freelancers sobre a contratação e estratégias de capacitação. Identificou-se elementos pouco criteriosos na contratação dos funcionários e no treinamento destes, demonstrando fortes indícios de precarização nas relações trabalhistas estabelecidas entre empresa e trabalhadores, incluindo remuneração com valores baixos e longas jornadas de trabalho. Apesar disso, a empresa parece não se importar com as consequências na qualidade do serviço prestado, já que o regime de terceirização acaba mitigando a percepção da responsabilidade pelo serviço prestado e, consequentemente, gerando poucos danos à imagem da empresa perante o público.

Palavras-chave: Eventos. Precarização do Trabalho. Reestruturação Produtiva.

\section{ABSTRACT}

This paper aims to discuss the precarious work established in one of the most relevant branches of tourism: the events sector. Despite occupying a strategic position for the economy and for tourist destinations visibility in the global market, the sector is characterized by subcontracted, temporary and informal employment relationships. These relationships emerge from the international financial model, from the flexible accumulation of capital, where the employment contract with all the rights and obligations previously defined and unchanged throughout its duration, has been changed to less rigid models, beginning with the so-called 'productive restructuring'. To exemplify these relationships, this study analyzed a company located in Rio de Janeiro specialized in public orientation in events and its contractors. It was investigated the perception of customers and employees about the services provided and the perception of freelancers on the hiring and training strategy. Few standards elements were identified in the process, showing strong signs of precariousness in professional work relations between the company and workers, like low-wages and long working hours. Despite this, the company does not seem to care about the consequences on the quality of the service provided, since the outsourcing regime ends up mitigating the perception of responsibility for the service provided and, consequently, generating little damage to the company's image before the public.

Keyword: Events. Precarious Work. Productive Restructuring. 


\section{INTRODUÇÃO}

Dentre os diversos aspectos positivos desencadeados pela atividade do turismo, o argumento da geração de emprego e renda aparece como um dos principais. O turismo gera inúmeros postos de trabalho e nos mais variados setores pois para que os viajantes se divirtam no destino turístico há trabalhadores executando tarefas diversas nos bastidores. Ou seja, em sua dinâmica de funcionamento, a atividade necessita de recursos humanos intensivos para operacionalizar a cadeia produtiva do turismo. Entretanto, em um primeiro momento a qualidade dos empregos motivados para o turismo não é questionada (Costa, 2008) e são poucos os estudos que se dedicam a analisar a precariedade existente em boa parte dos empregos do setor de turismo.

Estudos como os de Souza (2016) indicam que nos periódicos da área de turismo há poucos estudos dedicados a analisar, de forma qualitativa, o trabalhador e suas condições de trabalho. De acordo com a autora, alguns estudos até abordam aspectos da rotina de trabalho, mas com o foco no turista, nas empresas ou em aspectos relacionados à forma de inserção no mercado de trabalho, tais como os estudos de Tomazzoni (2007), Pimentel e Paula (2014), Agostinho e Mondo (2018) e Lima e Amaral (2018). Sabendo desta lacuna, esta pesquisa tem como objetivo principal discutir a precarização nas relações de trabalho estabelecidas no setor de eventos, um dos ramos mais relevantes do turismo.

Sendo assim, pretende-se neste artigo realizar uma análise qualitativa sobre as relações de trabalho estabelecidas em uma empresa de eventos e as consequências da precarização observada. Convém aqui acrescentar que esta pesquisa foi motivada pela experiência profissional de uma das autoras deste trabalho, que atuou no setor de eventos desde o ano 2015 até o ano de 2019. A partir desta experiência rotineira, várias condutas inadequadas foram observadas e decidiu-se investigar, através de técnicas de observação participante (Minayo, 1999) os impactos da contratação de funcionários terceirizados por empresas de eventos. Além da observação participante, foi realizada revisão bibliográfica sobre a temática da precarização das relações de trabalho, estudo de caso de uma empresa de eventos, entrevistas online com trabalhadores freelancers do setor de eventos e análise de conteúdo (Minayo, 1999) de postagens em redes sociais sobre os eventos da empresa estudada ${ }^{1}$.

O setor de eventos se destaca em muitos aspectos positivos, sendo um dos principais o marketing gerado para as cidades e possibilidade de alterar a realidade da região envolvida e da sociedade no geral (Barreto, 2003). Por outro lado, é preciso ressaltar que grande parte dos

\footnotetext{
${ }^{1}$ Os procedimentos metodológicos serão melhor apresentados no item 3 deste artigo.
} 
recursos humanos no setor se caracteriza por profissionais terceirizados (Associação Brasileira de Empresas de Eventos - ABEOC, 2013) e informais, ocupando funções com pouca, ou nenhuma, qualificação para tal (Guimarães, 2015), denotando assim um descompasso entre a posição estratégica do setor e a necessidade de garantir um serviço de qualidade com recursos humanos treinados para o exercício de suas funções.

Ressalta-se que a contratação temporária e a terceirização de serviços são estratégias observadas em um contexto mais amplo, advindas do modelo financeiro internacional, cujas implicações econômicas e político administrativas incluem o desemprego estrutural e o rápido aumento da pobreza e das desigualdades que tornam mais visível a situação de exclusão e a miséria em que se encontram inúmeros brasileiros (Oliveira, Oliveira, 2005).

O contrato de trabalho sólido, com todos os direitos e obrigações previamente definidos e inalterados ao longo de sua duração, vem sendo trocado por modelos menos rígidos, a partir da chamada 'reestruturação produtiva', com postos de trabalho sem vínculos trabalhistas, perda de benefícios indiretos, extensão da jornada laboral além do estabelecido pela legislação e transferência para os trabalhadores das responsabilidades de toda e qualquer imprevisibilidade do processo produtivo (Buonfiglio \& Dowling, 2006). No Brasil, esta situação foi "potencializada" no ano de 2017 com a aprovação da Lei ordinária 13.429 de 31 de março de 2017, no governo de Michel Temer, que modificou dispositivos da Lei 6.019, de 3 de janeiro de 1974 e autorizou a terceirização para todas as atividades de uma empresa.

Para melhor abordagem dos assuntos, este artigo está divido em duas seções principais. A primeira delas apresenta a revisão teórica e conceitual que subsidiaram as análises realizadas. E a segunda parte, os aspectos metodológicos de coleta e análise de dados do estudo de caso realizado. 


\section{ACUMULAÇÃO FLEXÍVEL, REESTRUTURAÇÃO PRODUTIVA E O SETOR DE}

\section{EVENTOS}

Nos Estados Unidos, o setor de eventos contribui com cerca de U\$ 446 bilhões para o PIB do país (Events Industry Council, 2018). No Brasil, o setor foi responsável, em 2013, pela geração $\mathrm{R} \$ 209,2$ bilhões de reais, o que corresponde a 4,3\% do PIB Nacional daquele ano (ABEOC, 2013). Só no Estado de São Paulo, o impacto anual de resultados de empresas expositoras de eventos, já chegou ao equivalente a 4,6\% do PIB Nacional de acordo com dados da UBRAPE em 2019 (União Brasileira dos Promotores de Feiras). Percebe-se, por esses dados, a importância do setor para o turismo e para a economia. Porém, apesar dessa posição estratégica, o setor se caracteriza por relações de trabalho baseadas em terceirizações, contratos temporários e informalidade (ABEOC, 2013; Guimarães, 2015). Cerca de 71,1\% dos trabalhadores do segmento de cultura e lazer (que envolve os espetáculos e atividades complementares) são informais (Instituto de Pesquisa Econômica Aplicada - IPEA, 2018).

A terceirização é caracterizada pela "contratação de serviços profissionais externos para atender a certas necessidades específicas de negócios" (Stair \& Raynolds, 2006, p. 49), para que a empresa siga focada apenas nos negócios em que atua diretamente (Giosa, 1997). Para Gonsalves (2001) a terceirização se baseia em contratar o serviço através de uma empresa que funciona como intermediador do contratado e contratante. Tal modalidade emergiu nos Estados Unidos com o início da Segunda Guerra Mundial, vindo da necessidade de produção de armamento para a guerra e a escassez de recursos humanos para produção (Petrin, 2015) e tomou novas formas dentro do contexto de reestruturação produtiva, conforme será abordado mais adiante. Já o trabalho temporário é caracterizado como uma alternativa para empresas que necessitem complementação do trabalho de seus empregados, "sempre em situações excepcionais de serviço, para atender a uma necessidade transitória de substituição de pessoal regular ou permanente (trabalhador efetivo)" (Pinto, 2004, p. 14).

O trabalho informal e a noção de 'informalidade', de acordo com Guimarães (2015), nasce nos anos 1960 para explicar a dificuldade da incorporação produtiva de trabalhadores (principalmente migrantes) vindos das áreas rurais. Neste contexto surgem algumas teorias, tais como: i) a da 'modernização' (que encarava a informalidade como situação transitória, já que o desenvolvimento econômico levaria o trabalhador à condição de assalariado); ii) da 'marginalidade' (que enfatizava as dificuldades de superar o desequilíbrio estrutural); iii) da 'dependência (que indicava uma distinção conceitual entre o exército de reserva, que ocuparia uma posição no capitalismo e precisaria ser reproduzido; e o trabalho excedente, uma "massa 
marginal” sem função onde se encaixaria os trabalhadores informais); e iv) da "superexploração", que mostra como o trabalho informal era funcional para a redução do custo de reprodução social da força produtiva nas cidades (Guimarães, 2015).

Para Guimarães (2015) a exploração do trabalho encontra-se atualmente em um contexto em que a informalidade se confunde com flexibilização e desregulação, demonstrando o sucesso do modelo neoliberal - a exemplo do Carnaval de rua do Rio de Janeiro, com milhares de ambulantes a serviço de cervejarias sem nenhuma garantia trabalhista de forma normalizada pelo poder público; ou ainda com os programas de voluntariado de megaeventos como as Olimpíadas, quando são mobilizadas milhares de pessoas para garantir o lucro das entidades privadas.

Mesmo nas funções formais, o modelo de exploração do trabalho atual deixa para trás o modelo clássico fordista, pregando uma maior participação do trabalhador nas decisões que toma em seu ambiente de trabalho, exigindo, em contrapartida, uma maior demanda por sua subjetividade, uma busca constante por aumento de produtividade e redução de custos (Jost, Fernandes, \& Soboll, 2014; Oltramari, Paula, \& Ferraz, 2014).

$\mathrm{O}$ advento da racionalidade neoliberal (que tem sua origem na recessão da década de 1970 e suas consequências como desemprego, austeridade fiscal, dentre outros) impulsionou a adoção de um modelo que tem como características principais o incentivo à privatizações de empresas públicas, aos movimentos de desregulamentação da economia e o argumento de que a liberdade que se dá aos atores privados é sempre mais eficaz do que a intervenção direta ou a regulação pública (Harvey, 2005; Dardot \& Laval, 2016). Essa gama de novas experiências no domínio da organização industrial e da vida social e política representaram um regime de acumulação inteiramente novo, associado com um sistema de regulamentação política e social bem distinta, denominado por Harvey (1998) de 'acumulação flexível', que se apoia na flexibilidade dos processos e dos mercados de trabalho, dos produtos e padrões de consumo.

Esse poder de flexibilidade e mobilidade permite que empregadores exerçam maiores pressões sobre a força de trabalho enfraquecida pelo surto de deflação. A acumulação flexível implica o desemprego "estrutural", rápida destruição e reconstrução de habilidades, ganhos modestos e o retrocesso do poder sindical, dando início a uma reestruturação radical no setor trabalhista. A volatilidade do mercado, o aumento da competição e do estreitamento das margens de lucro, faz com que os empregadores tirem proveito do enfraquecimento do movimento sindical e do grande contingente de mão-de-obra excedente impondo regimes e contratos de trabalho mais flexíveis. Além disso, o modelo de competição advindo das empresas se ampliou 
para outros aspectos da vida dos sujeitos. Dardot e Laval $(2016 ; 2017)$ indicam a forma como isso ocorreu.

Até os anos 1970, o desemprego, desigualdades sociais e inflação eram problemas atribuídos ao capitalismo que, no entanto, passaram a ser problemas atribuídos ao Estado. Isso ocorreu a partir de uma crítica aos mecanismos de assistência social, com o discurso de que eles eximiam os indivíduos de suas responsabilidades na sociedade. Com essa individualização, todas as formas de 'crise social' passam a ser percebidas como 'crises individuais'; as desigualdades fruto da responsabilidade das escolhas; e as relações sociais passaram a agir seguindo a forma geral da contratualização. Assim, o ideal de eficácia da empresa passa a ser aplicado no nível individual e suas qualidades esperadas no universo social são aquelas consideradas 'recursos' indiretos para a empresa (Dardot \& Laval, 2016).

Nesse contexto, a organização passa a aplicar técnicas para aumento da produtividade, que alteram o modo do trabalho ser produzido, a partir da apropriação da subjetividade do trabalhador (Oltramari, Paula, \& Ferraz, 2014). O efeito desejado com a aplicação de refinadas técnicas de motivação, estímulo e incentivo é que o indivíduo trabalhe para a empresa como se trabalhasse para si mesmo, para sua própria eficácia e como se isso fosse comandado pelo seu próprio desejo, com base nesse paradigma de 'empresa pessoal' ou 'indivíduo-empresa' e assim, todas as ações do trabalhador passam a visar a sobrevivência na competição (Dardot \& Laval, 2016).

Assim, a racionalidade neoliberal extrapola os limites da empresa a partir da fusão entre 'ser bem-sucedido na carreira' e 'ser bem sucedido na vida'; e as fronteiras entre o dentro e fora da empresa se afrouxam com o desenvolvimento tecnológico e mecanismos de subcontratação, emprego temporário, trabalho por projeto, consultorias externas, dentre outras modalidades, todas alinhadas aos preceitos da acumulação flexível. (Dardot \& Laval, 2016). A essa nova política de relações soma-se ainda o contexto de reorganização e reconversão de ramos industriais com grandes investimentos em tecnologias de ponta; utilização de novos padrões de gestão/organização do trabalho e da produção através da generalização do modelo japonês (qualidade total, terceirização); novas tecnologias de base microeletrônica (automação, informatização) (Druck \& Franco, 1997). Todas estas mudanças se concretizam em um cenário de enfraquecimento do poder dos sindicatos de trabalhadores e suas relações com o patronato que, em geral, visam enfraquecer a representação coletiva em prol de negociações individuais e diretas com os trabalhadores (Druck, Franco, 1997).

O contrato de trabalho sólido, com todos os direitos e obrigações previamente definidos e inalterados ao longo de sua duração vem sendo progressivamente trocado por modelos menos 
rígidos, fato muito comum no setor de turismo e em especial no segmento de eventos. Estabelece-se assim o novo termo para o fenômeno da flexibilização das relações de trabalho, ou nova denominação para a antiga "subcontratação" - a terceirização. Esta opção trabalhista, de acessório ao processo produtivo, torna-se elemento fundamental, dentro da nova onda modernizadora. Apela-se para "a vocação da empresa", que deve transferir, sair de tudo que não represente seu objetivo-fim. Mas, curiosamente, transfere a terceiros cada vez mais a atividadefim, a produção parcial ou mesmo total (Buonfiglio \& Dowling, 2006).

A chamada 'reestruturação produtiva' tornou o recurso à terceirização um imperativo, sendo possível inseri-la nas etapas de produção, manutenção, distribuição e vendas. Com isto, cria-se uma série de trabalhadores dos mais variados cargos sem vínculo trabalhista com a empresa; surgem também os "postos de serviço", unidades da própria empresa, interiorizadas, que apesar de manter a relação contratual legal, não oferecem nenhum outro benefício; ou ainda da figura de empresas faccionistas ${ }^{2}$, muitas vezes criadas para atender a uma parte da produção da empresa principal.

O setor do turismo, considerado por autores como Maio (2006) como um braço da globalização, não estaria, portanto, excluído desse movimento e suas consequências, e seus profissionais são constantemente alvo da precarização das relações trabalhistas e do sequestro da subjetividade no contexto do indivíduo-empresa. Destacando-se ainda que, no turismo, além de multifuncionais e cooperativos, os trabalhadores no turismo devem ser poliglotas, ter conhecimento de relações interpessoais, bem como de aspectos históricos e geográficos dos lugares em que atuam, exigências elevadas que contrastam com as condições objetivas de trabalho e remuneração (Meliani \& Gomes, 2010).

Além da precarização nas relações de trabalho, destaca-se ainda que algumas empresas optam pela contratação de recursos humanos pouco qualificados, de forma a reduzir ainda mais os custos de suas operações. Oliveira (2007) aponta que um dos aspectos que podem auxiliar o bom desenvolvimento do evento é a preparação da equipe de todos os setores para que não haja desencontros na transmissão de informação e execução dos serviços. A qualificação e capacitação dos profissionais envolvidos são questões de extrema importância para qualquer

\footnotetext{
${ }^{2}$ Faccionistas: empresas muitas vezes criadas especialmente para atender uma grande empresa, às vezes ligadas a algum seu empregado de alto ou médio escalão; muitas ainda, operam com capital e equipamento fornecido ou financiado por ela. Parte da produção passa a ser realizada nessas pequenas ou médias empresas, controladas por um supervisor de qualidade ou de produção da empresa-mãe. Nota-se uma forte relação de dominaçãosubordinação entre uma e outra. Muitas vezes a faccionista toma a forma de falsa "cooperativa de produção". No entanto, independentemente da forma que assumem, prevalecem nelas precárias condições de trabalho, longas jornadas, baixos salários; quando há contrato de trabalho, nenhum outro benefício além do salário mínimo; quando se trata de trabalho ilegal - "informal" ou sob o regime de "cooperativa" - nemisso. (Buonfiglio \& Dowling, 2006, p. 5).
} 
oferta de serviço e devem andar em conjunto para que o resultado seja positivo (Alves \& Vieira, 1995). Ou seja, a ausência dessa preocupação pode gerar impactos negativos na qualidade do serviço oferecido e na imagem da empresa junto ao seu público.

Parte do empresariado justifica essa situação culpando os próprios profissionais, indicando uma fraca qualificação dos trabalhadores no segmento de eventos (Costa, 2008). Martoni e Alves (2019) destacam que ao situarem a qualificação e o esmero profissional como questões puramente subjetivas, muitos desconsideram as relações permeadas pelo capital de caráter efetivamente produtivo.

Além disso, contrapondo essa justificativa, recentemente, no Brasil e impulsionados pelos megaeventos que ocorreram no país, uma série de cursos na área do turismo foram ofertados de forma gratuita pelo poder público no âmbito do Programa Nacional de Acesso ao Ensino Técnico e Emprego (PRONATEC). Cursos como de agente de informação turística, auxiliar de garçom, barista, bartender, cerimonialista, organizador de eventos, recepcionista em meios de hospedagem, entre outros (Relatório Programa Educação Para Todos no Brasil, 2014) e estudos apontam que muitos egressos desse programa encontraram dificuldades de inserção no mercado de trabalho (Fratucci, Bantim, \& Melo, 2017), inferindo-se, portanto, que há recursos humanos qualificados disponíveis, porém eles não são utilizados/ valorizados. Além disso, dependendo do evento, mesmo profissionais qualificados necessitam de alguma capacitação ou treinamento específico para sua atuação (Trigo, 2001). Nesse sentido, destacase que a qualificação está relacionada à formação de um profissional e a capacitação é a responsável para evolução constante desse aplicado colaborador já especializado (Alves \& Vieira, 1995)

Nem sempre, porém, as empresas demonstram essa preocupação, privilegiando a diminuição de seus custos operacionais (investir em qualificação dos seus trabalhadores, por exemplo) e o foco no aumento dos lucros. Ou seja, agindo assim denota pouco comprometimento com os profissionais envolvidos e com a qualidade dos recursos humanos e dos serviços prestados.

\section{ASPECTOS METODOLÓGICOS}

Para exemplificar o modelo de contratação no setor de eventos e refletir sobre a precarização das relações de trabalho no setor, realizou-se um estudo de caso em uma empresa de eventos especializada em orientação de público. Esta tem como principal regime de contratação a terceirização e, para expor o nome desta empresa, adotamos o nome fictício de "Mario Braparst". 
A "Mário Braparst" é uma empresa sediada na cidade do Rio de Janeiro, trabalha principalmente com eventos de médio e grande porte, fazendo também a orientação de público em transportes, estratégia de marketing, criação e design de arte visual para empresas entre outros. A empresa possui em seu portfólio eventos importantes, de alcance midiático mundial e já prestou serviços para o grupo que administra atrativos turísticos como as Cataratas do Iguaçu, o AquaRio e Paineiras Corcovado. Sua principal forma de trabalho é a contratação de freelancers, e possuía, até o final do ano de 2019, cerca de 20 colaboradores com contrato efetivo pela CLT e 80 contratos intermitentes. Para embasar teoricamente as análises sobre as condições do trabalho terceirizado nesta empresa e a avaliação do impacto que essas contratações têm no desenvolvimento dos serviços turísticos prestados, foi realizada uma revisão teórica sobre as questões da precarização do trabalho e reestruturação produtiva neoliberal (Harvey, 1988; 2005; Buonfiglio \& Dowling, 2006; Dardot \& Laval, 2016; 2017).

Para verificação da percepção dos contratados sobre o modelo de contratação e estratégia adotada pela empresa para capacitação, foi realizada pesquisa exploratória com os seus trabalhadores terceirizados (atuais ou que já haviam realizado algum trabalho esporádico ali). Vieira (2002, p. 65) aponta que "a pesquisa exploratória é usada em casos nos quais é necessário definir o problema com maior precisão e identificar cursos relevantes de ação ou obter dados adicionais antes que se possa desenvolver uma abordagem”. Os dados foram obtidos através de formulário de pesquisa online via ferramenta Google Forms. O formulário foi disponibilizado (no período de 10 de setembro à 30 de setembro de 2019) em grupos virtuais (WhatsApp, principalmente) de pessoas que prestam serviços de forma terceirizada ou freelancers em eventos.

Também foram analisados conteúdos postados em redes sociais tanto da empresa "Mario Braspart" quanto de empresas contratantes de seus serviços para verificação de depoimentos de clientes e funcionários em relação aos serviços prestados para analisar se havia elogios ou críticas dos participantes de eventos organizados pela "Mario Braspart".

As anotações do trabalho de campo de uma das autoras - que vivenciou a experiência de ser freelancer, passou pelos processos de recrutamento da empresa e atuou como funcionária temporária da mesma - possibilitou receber informações por outros funcionários (tanto durante o evento quanto através de grupos em redes sociais) e uma rica aproximação in locu com todas as etapas de execução de um evento.

Segundo Minayo (1999), uma pesquisa possui três etapas principais: a) fase exploratória, na qual se amadurece o objeto de estudo e se delimita o problema de investigação; b) fase de coleta de dados, em que se recolhem informações que respondam ao problema; e c) 
fase de análise de dados, na qual se faz o tratamento, por inferências e interpretações, dos dados coletados. As informações obtidas, em ambas as etapas, foram analisadas através das técnicas da análise de conteúdo preconizadas por Minayo (1999) e levando em consideração o contexto da racionalidade neoliberal e da precarização das relações de trabalho.

\section{A CONTRATAÇÃO DOS PROFISSIONAIS NO SETOR DE EVENTOS - O CASO DA EMPRESA "MARIO BRAPARST"}

Durante o período de coleta de dados para a pesquisa, no que tange às formas de contratação, foi verificado que as vagas ofertadas pela empresa "Mario Braspart" costumavam ser disponibilizadas através das redes sociais, sendo o WhatsApp a principal delas. As vagas circulam por grupos compostos por freelancers ${ }^{3}$ e por grupos de pessoas que trabalham com figuração em teledramaturgia e comerciais (Figura 1). A empresa indica, muitas vezes, que não é necessário ter experiência em atendimento ao público.

Figura 1 - Chamada para trabalho em evento

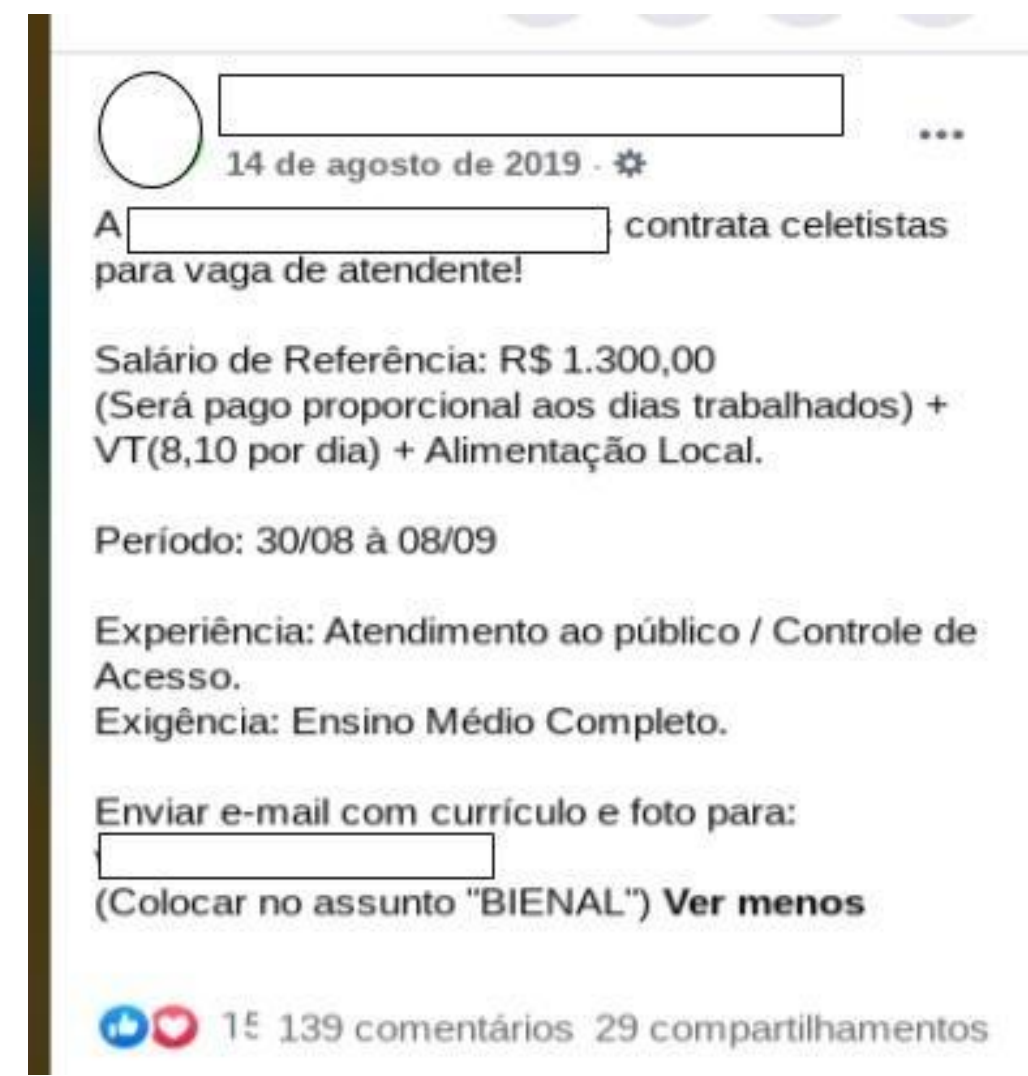

Fonte: Reprodução da página da empresa, 2020.

\footnotetext{
${ }^{3}$ Trabalhadores autônomos, muitas vezes informais, atuando de forma terceirizada ou temporária.
} 
Nessa chamada, destacamos a ausência de uma informação clara sobre o valor da remuneração das diárias e forma de pagamento. Coloca-se um valor de $\mathrm{R} \$ 1300,00$ como salário mensal de referência, mas o pagamento é feito proporcionalmente aos dias trabalhados (9 dias) no total.

Figura 2 - Chamada para trabalho

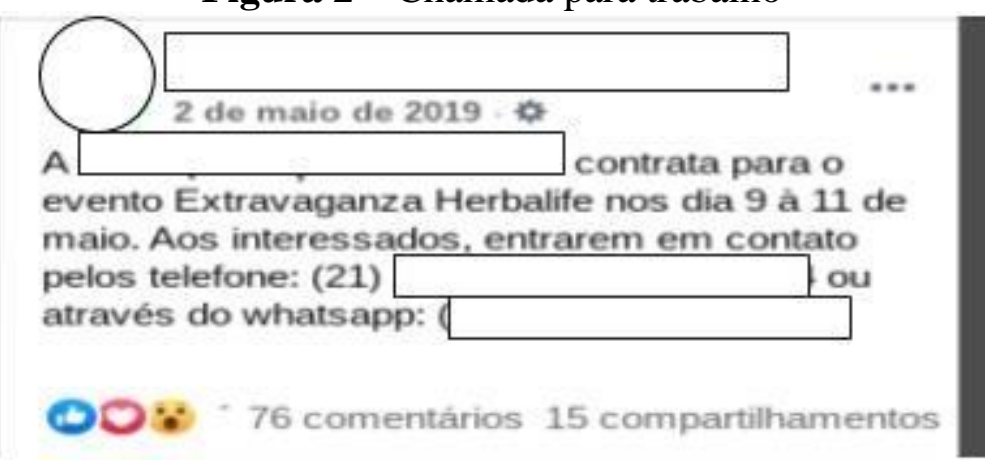

Fonte: Reprodução da página da empresa, 2020.

Em ambas as chamadas destacamos os intervalos pequenos entre as datas de recrutamento e de realização do evento, gerando pouco tempo para preparação e treinamento dos profissionais para exercício de suas funções. Destaca-se ainda que apesar de ser comum esta forma de divulgação, há também as contratações feitas por indicações de pessoas que já trabalharam na empresa e passam a indicar outras pessoas. Foi observado que a "contratação" é feita por acordos e conversas por meio do aplicativo WhatsApp e, dessa forma, o contratante tem contato pessoal com o contratado apenas no dia do evento. Esse tipo de contratação informal faz com que as desistências sejam frequentes, e, em alguns casos, os funcionários da empresa que são permanentes, contratados, via CLT, atuam para cobrira falta de pessoal para que o posto designado não fique vazio.

Foi observado ainda que nos dias dos eventos, há uma equipe responsável pelo trabalho de campo (supervisores) que analisam o trabalho dos contratados, para garantir que o atendimento seja feito. Entretanto, em alguns eventos, o número de freelancers é muito maior do que a quantidade de supervisores, o que abre brechas para falhas, alinhado à falta de treinamento dos mesmos para exercício da função. Essa situação vai ao encontro das considerações de Buonfiglio e Dowling (2006) acerca das terceirizações, e às de Guimarães (2015) sobre a exploração do trabalho no setor de eventos no Brasil, ambas aqui descritas anteriormente.

Sobre isto, convém aqui expor as anotações de campo realizadas durante um grande evento esportivo Ultimate Fighting Championship (UFC), ocorrido no ano de 2019. Neste dia a equipe era formada por aproximadamente 10 supervisores e cada supervisor era responsável 
por 20 freelancers (staff). Levando em consideração a quantidade reduzida de supervisores responsáveis por cada equipe, alguns problemas foram verificados, tais como atrasos de liberação para intervalo, postos vazios e sobrecarga de função. Embora o evento tivesse duração de 3 horas, a equipe teve uma carga horária de trabalho superior a 9 horas. Além do mais, no decorrer do evento, a equipe de staff foi sendo reduzida devido às atitudes inadequadas de determinados freelancers, tais como: tomar o assento do espectador durante o evento, consumo de alimentos da área vip, discussão e brincadeiras no rádio de comunicação e abandono de posto. Todas as "baixas" foram descontadas da empresa e o freelancer não recebeu a diária. O impacto na qualidade do serviço prestado foi sentido pelo público presente, gerando reclamações com a equipe local.

É comum as empresas contratantes dos serviços terceirizados da "Mario Braspart" possuírem até 30 dias, após o evento, para remunerá-la pelos serviços prestados. Desta forma, é somente após este processo que os freelancers recebem seu pagamento. O valor é contabilizado por diária. A empresa não fornece auxílio para o transporte dos contratados e, geralmente, oferece alimentação durante o evento.

Além da contratação de freelancers, a empresa também possui alguns contratos intermitentes ${ }^{4}$. Nesse método, adotado pela empresa no ano de 2019, o indivíduo passa a ter vínculo com a empresa tendo carteira assinada. No evento da Bienal do Livro, por exemplo, a empresa assinou a carteira de aproximadamente 80 colaboradores com regime intermitente com duração de um ano, podendo ser rompido a qualquer momento caso o colaborador deseje. A empresa tem a política de contratar o mesmo colaborador até 3 eventos seguidas, para seguir a linha de contratação intermitente.

Entendendo que esse regime de contratação pouco criterioso, somado com a falta de treinamento e capacitação dos funcionários para atuação nos eventos poderia gerar impactos negativos na imagem da empresa, realizou-se uma verificação nas redes sociais da "Mario Braparst" e em seus contratantes com o intuito de captar registros positivos e negativos dos freelancers ou do público dos eventos sobre a empresa.

A busca na rede social da empresa foi feita através da sua página no Facebook com filtro da busca no período entre 2013 e 2019 , e o principal foco da pesquisa foram relatos sobre as contratações e serviços. A Figura 2 retrata a forma de trabalho encontrada pelo freelancer de desenvolver seu trabalho pela empresa.

\footnotetext{
${ }^{4}$ Prestação de serviços sem continuidade, com períodos alternados de execução e com períodos de inatividade, podendo ser em horas, dias ou meses.
} 
Figura 3 - Registro do Facebook na página da empresa

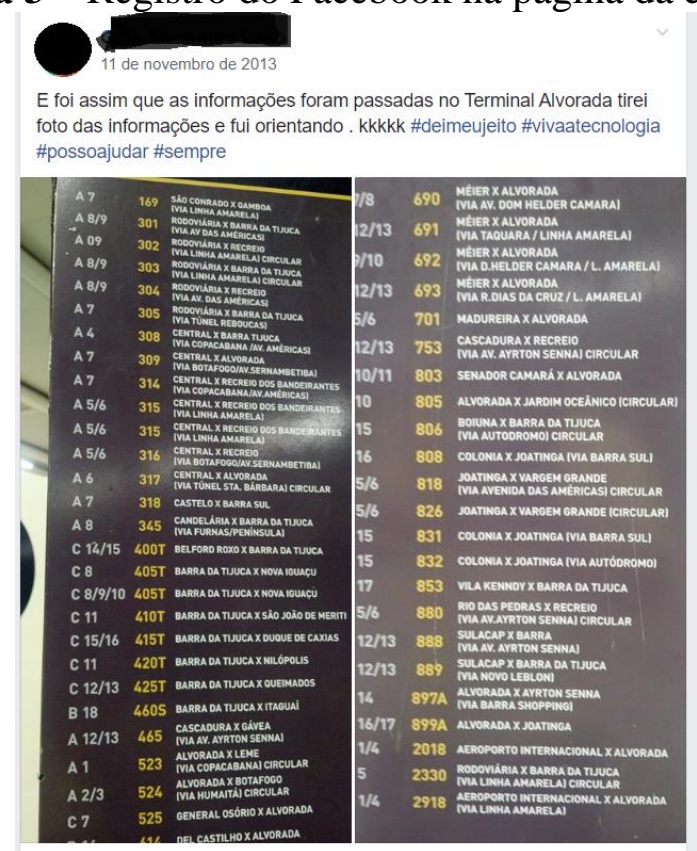

Fonte: Reprodução página do Facebook, 2020.

A figura 3 ressalta, portanto, a falta de orientação que os freelancers recebem para execução de seus serviços.

Já a figura 3 apresenta uma reclamação em relação à remuneração dos serviços prestados:

Figura 4 - Feedback do freelancer sobre o serviço de contratação

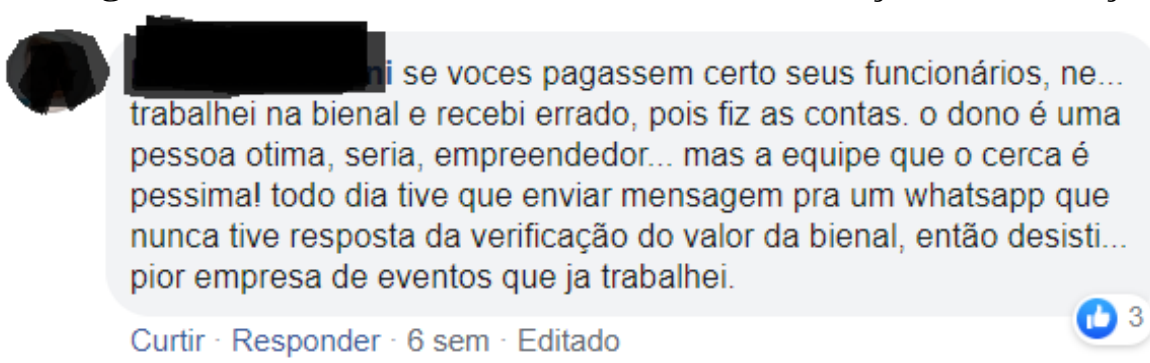

Fonte: Reprodução página do Facebook, 2020.

Esses depoimentos ressaltam fragilidades da empresa em relação aos serviços prestados e ao tratamento aos profissionais envolvidos. Teberga (2020) indica que a precarização do trabalho é recorrente no setor de eventos em razão de sua alta informalidade e se manifesta principalmente nas jornadas exaustivas de trabalho, e isso se manifesta desde grandes eventos (mesmo com toda fiscalização envolvida) até os pequenos eventos, que não envolvem tanta visibilidade.

Apesar dessas ações, ao buscarmos nas redes sociais depoimentos do público em relação aos serviços prestados, apesar de algumas reclamações identificadas em relação ao tempo de 
espera e qualidade de atendimento, o número identificado foi pouco expressivo. Acreditamos que isso ocorra pois, como o serviço é terceirizado, o público não identifica a empresa "Mario Braparst" como a responsável pela prestação de serviços, mas sim a empresa contratante do evento. Uma das consequências da terceirização dos serviços é justamente a mitigação da percepção do público sobre a empresa responsável efetivamente pela prestação do serviço e, tal fato, conforme exposto por Buonfiglio e Dowling (2006) acaba transferindo para os trabalhadores, que estão na ponta do processo e lidando diretamente com o público, as responsabilidades de toda e qualquer imprevisibilidade do processo produtivo e consequentes reclamações.

Por isso, ampliamos a busca nas redes sociais de algumas empresas contratantes e identificamos reclamações referentes a serviços que, na verdade, foram realizados pela "Mario Braparst", conforme reproduzidos nas figuras 5 e 6 :

Figura 5 - Feedback do serviço prestado na página do contratante

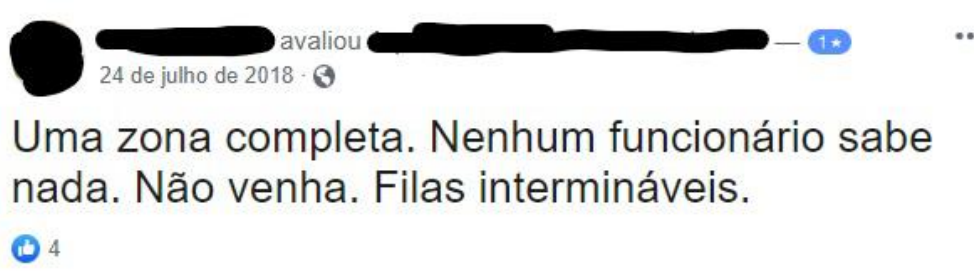

Fonte: Reprodução de avaliação encontrada em rede social do contratante da empresa "Marios Braparts", 2020.

A figura 5 se refere a uma reclamação sobre o serviço de orientação fornecido pela empresa "Mario Braparst" em um atrativo turístico carioca, de visibilidade internacional. A maior concentração de reclamações encontradas se refere ao atendimento e qualificação dos funcionários (figura 6). Conforme colocado por Costa (2008) no início deste trabalho, a fraca qualificação é usualmente apontada como um fator de insucesso, porém essa culpa recai no próprio profissional e não na empresa que deveria se responsabilizar minimamente tanto pela escolha de profissionais qualificados como pela capacitação dos mesmos para trabalhos específicos, sendo desconsideradas, portanto, as relações de trabalho permeadas pelo capital, conforme considerações de Martoni e Alves (2019). 
Figura 6 - Feedback do serviço prestado na página do contratante

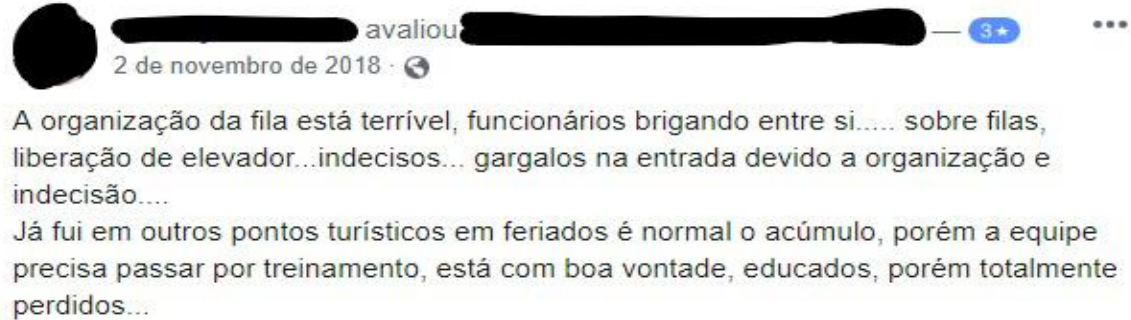
perdidos.

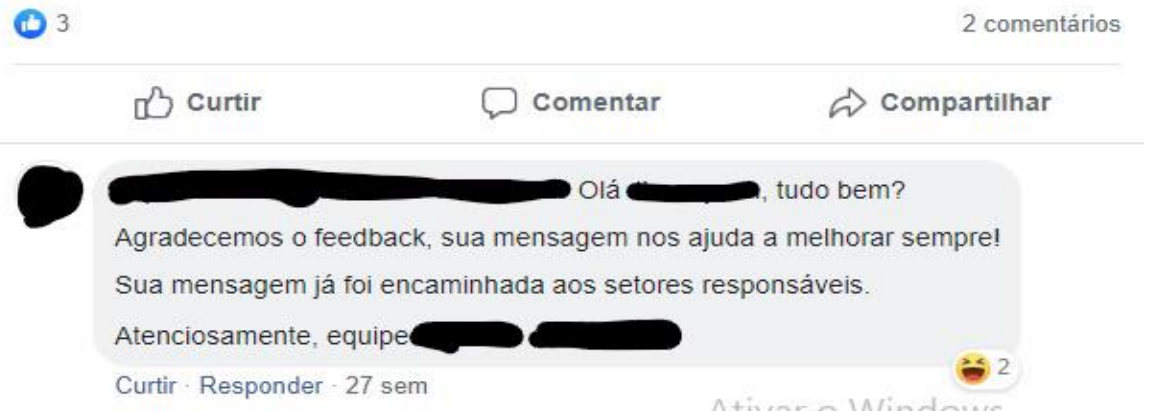

Fonte: Reprodução de avaliação encontrada em rede social do contratante da empresa "Mario Braparst", 2020.

Kotler (1998) afirma que a qualidade é uma reunião de serviços de caráter específico ou de um produto que resultam na satisfação do cliente. Como pode ser visto na seção anterior, a qualificação e treinamento do grupo de funcionários é essencial para o desenvolvimento positivo do serviço, para que não ocorram retornos negativos para a empresa contratante, como é o caso das imagens acima.

Durante a pesquisa foi levantando também o perfil dos freelancers que atuam no setor de eventos, tanto no que se refere à sua qualificação quanto às percepções em relação ao treinamento e capacitação. Assim, como já mencionado, foi elaborado um formulário online através da ferramenta Google Forms e postado em grupos com pessoas que prestam serviços de forma terceirizada ou freelancers, tendo retorno de 36 formulários validados.

Em relação aos dados socioeconômicos dos respondentes, obtivemos os seguintes retornos:

1. $47,2 \%$ tem entre 18 e 24 anos,

2. $41,7 \%$ têm entre 25 e 35 anos e $11,1 \%$ têm entre 26 e 45 anos,

A maior parte são mulheres, $66,7 \%$ se identificaram com o gênero feminino.

A renda familiar dos entrevistados é de:

1. até 2 salários mínimos para $47,2 \%$ dos entrevistados;

2. 30,6\% possui entre 2 a 4 salários mínimos;

3. 13, $9 \%$ possui renda entre 4 e 10 salários mínimos;

4. 5,6\% acima de 10 salários mínimos e 
5. $2,8 \%$ optaram por não responder.

Sobre o grau de escolaridade,

1. $47,2 \%$ dos entrevistados possuem ensino superior incompleto;

2. $38,9 \%$ ensino superior completo e

3. $13,9 \%$ ensino médio completo.

Em relação à qualificação, foram obtidos os seguintes resultados:

1. $72,2 \%$ dos entrevistados possuem um segundo idioma;

2. $34,6 \%$ não possuem nenhum tipo de capacitação voltado para Turismo;

3. 9,4\% possuem curso técnico relacionado ao setor de eventos;

4. 50,8\% possuem a graduação em Turismo;

5. 5,4\% curso técnico em recepção de eventos.

Nesse sentido, ressalta-se o grande número de respondentes que são graduados em turismo e falam um segundo idioma, possuindo, portanto, qualificação para atuar no setor. Contudo, mesmo este tipo de profissional qualificado necessita de capacitação e treinamento para prestação de informações e desempenhar tarefas específicas de cada evento.

A figura 7 mostra a percepção dos entrevistados sobre as habilidades necessárias no momento de contratação. Nessa questão, os números ultrapassam 100\% pois os entrevistados selecionaram mais de uma opção.

Figura 7 - Fatores relevantes para contratação

\section{Quais fatores achou relevante para conseguir o emprego na área de} Turismo/Eventos?

36 respostas

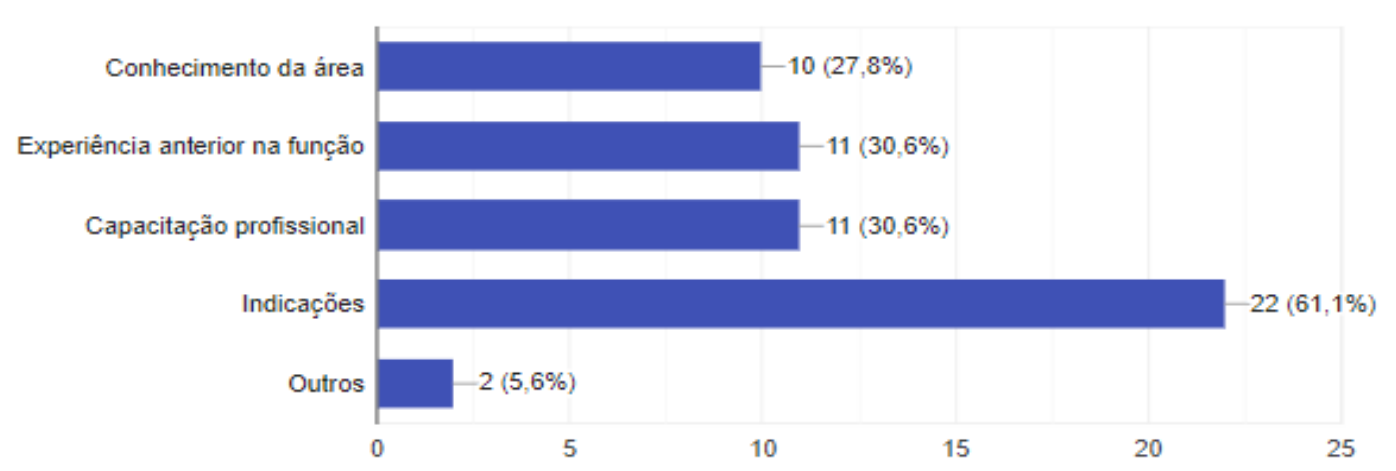

Fonte: Autor baseado em formulário de pesquisa aplicada, 2019. 
Percebe-se que a indicação (network) efetivamente é o principal fator de contratação, em detrimento à aspectos técnicos como a qualificação.

Nesse sentido, foi questionado também se a qualificação era vista como diferencial na atuação do trabalho e, $77,8 \%$ das respostas positivas, enquanto $22,2 \%$ dos respondentes afirmaram que a qualificação não era um diferencial.

Além disso, 77,8\% dos respondentes afirmaram sentir falta de preparo e treinamento oferecido por parte das empresas para exercício de suas funções.

Por fim, o formulário apresentou uma pergunta aberta, para que os respondentes pudessem expressar livremente o que poderia lhes auxiliar a desempenhar melhor suas funções do setor de eventos. Analisando as respostas livres, foi possível observar que por mais que cada entrevistado tenha sua experiência no segmento, a maioria mencionava como dificuldade a questão da falta de treinamento e preparação para exercer a função no evento contratado. Outras respostas recebidas foram: críticas com relação a falta de transparência por parte da empresa sobre horas trabalhadas, a ausência de limites e respeito com a carga horária de trabalho; necessidade de aumento de oportunidades para pessoas qualificadas; capacitação para lidar com o evento; ofertas de cursos para exercer a função nos eventos e até mesmo um relato levantando o descaso do setor e a falta de seriedade por parte dos contratantes em valorizar o profissional de eventos.

\section{CONSIDERAÇÕES FINAIS}

A temática da precarização das relações de trabalho em turismo, principalmente as questões da terceirização e contratos temporários (em razão da sazonalidade da atividade) não é uma discussão nova, contudo é pouco abordada em trabalhos acadêmicos relacionados com a área de eventos.

No decorrer do estudo de caso na empresa "Mario Braspart" foi possível identificar a falta de profissionalismo de alguns produtores de eventos ao encarar de forma simplista o trabalho de organização de um evento, seja qual for o seu segmento. As observações de campo proporcionaram uma rica possibilidade de vivenciar e observar a forma como as empresas lidam com o profissional de eventos, através de contratos de trabalho informais, sem treinamento, remuneração baixa (demora para efetivar o pagamento da diária) e ausência de pagamento do vale transporte. Além do mais, chama a atenção a baixa seletividade profissional no momento da contratação com o objetivo de diminuir os custos dos profissionais, selecionando pessoas fora do perfil de trabalho, não remunerando adequadamente um freelancer bilíngue, por exemplo, renunciando à qualidade na oferta de serviço. 
Essa ausência de critérios de seleção por parte da empresa no momento da contratação dos profissionais freelancers e a ausência de treinamento para exercício de suas funções, além de desvalorizar o profissional qualificado, coloca em risco o bom desempenho do evento e, em casos extremos, expõe o público aos riscos que são resultados da falta de preparo por parte da equipe responsável pelo desenvolvimento do evento.

Sem um preparo, um plano conjunto com as políticas públicas da cidade em que o evento será realizado, a exposição a riscos é incalculável, especialmente considerando que a empresa estudada atua em um dos mais conhecidos destinos turísticos do país. Além do mais, convém ressaltar que a cidade do Rio de Janeiro finalizou recentemente um ciclo de megaeventos (com orçamentos bilionários), que deveriam ter deixado como legado uma maior expertise e profissionalismo para atuação na área, considerando os ganhos econômicos e de visibilidade adquiridos com a realização dos mesmos.

A falta de critérios de seletividade dos funcionários que atuam nas empresas organizadoras de eventos, e o descaso no treinamento dos mesmos para atuarem em eventos diversos, retratam uma precarização na relação entre empresa e trabalhadores, onde a primeira abre mão da qualidade do serviço em troca de recursos humanos baratos, desqualificando o profissional apto para exercer a função e ajudando a desvalorizar sua formação. Agindo assim, a empresa contratada para organizar o evento parece não se importar com as consequências na qualidade do serviço prestado, já que o regime de terceirização acaba mitigando a percepção da responsabilidade pelo serviço prestado e a imagem da empresa acaba não sendo afetada. Evidentemente, essa é a realidade que se apresenta na empresa estudada, sendo necessários outros estudos, em outros contextos, para realização de um diagnóstico sobre as relações de trabalho que se estabelecem no setor de eventos no país como um todo.

Para finalizar, convém aqui citar que a pesquisa foi realizada e encerrada antes da pandemia do coronavírus. Desde meados do mês de março de 2020, até a presente data, todas as atividades que envolvem aglomeração de pessoas foram canceladas no Brasil em razão do risco de contaminação. O impacto da pandemia no turismo foi, e continua sendo, enorme. Contudo, a atividade envolve inúmeros setores, com graus de impactos diferenciados no contexto da pandemia, alguns já retomaram as suas atividades e outros ainda não.

O setor de eventos foi um dos mais impactados, tendo em vista as medidas que visam conter o vírus ao não permitir aglomerações, e ainda não há previsão de retorno das atividades na maioria das cidades brasileiras. Teberga (2020) indica que, nesse panorama, além do grande impacto no faturamento das empresas, os trabalhadores do setor sofrem com a situação, e, já 
estando em situação de informalidade, dependem exclusivamente das políticas de seguridade social.

Apesar de ainda não ser possível fazer previsões sobre como será a retomada do setor de eventos, certamente será baseado em normas rígidas de protocolos de segurança sanitária. Desta forma, será preciso criatividade e políticas públicas de apoio aos empresários do setor para o investimento nas adaptações que garantirão a segurança dos envolvidos e a retomada dos empregos - com especial cuidado para a contratação de profissionais capacitados, oferta de treinamento para os mesmos pensando também nos novos protocolos de segurança e - esperase - remuneração de forma justa para o desempenho de tais funções.

\section{REFERÊNCIAS}

Alves, E. L. G., \& Vieira, C. A. (1995). Santos Qualificação Profissional: Uma proposta de Política Pública. Planejamento e Políticas Públicas, (12).

Agostinho, H., \& Mondo, T. S. (2018). Os desafios da empregabilidade dos haitianos na hotelaria de Florianópolis. Revista de Turismo Contemporâneo, 6(2), 189-210,

Associação Brasileira de Empresas de Eventos - ABEOC BRASIL. (2013). II Dimensionamento Econômico da Indústria de Eventos do Brasil. SEBRAE Nacional.

Barretto, M. (2003). Planejamento e organização de turismo. Campinas: Papirus

Buonfiglio, M. C., \& Dowling, J. A. (2006). Reestruturação produtiva na indústria de transformação do nordeste: Fortaleza, Natal, João Pessoa e Recife. Recuperado em 07, setembro, 2009, de http://www.cchla.ufpb.br/unitrabalho/gtt1/livro/livrcap5.html

Costa, J. H. (2008). Trabalhadores de verão: políticas públicas, turismo e emprego no litoral potiguar. Dissertação de Mestrado em Geografia, Universidade Federal do Rio Grande do Norte, Natal, Rio Grande do Norte, Brasil.

Dardot, P., \& Laval, C. (2016). A nova razão do mundo: ensaio sobre a sociedade neoliberal. (1a. ed.). São Paulo: Boitempo.

Dardot, P., \& Laval, C. (2017). Comum: ensaio sobre a revolução no século XXI. São Paulo: Editora Boitempo.

Druck, G., \& Franco, T. (1997). A degradação do trabalho e os riscos industriais no contexto da globalização, reestruturação produtiva e das políticas neoliberais. In Franco, T. (Org.). Trabalho, riscos industriais e meio ambiente. Salvador: EDUFBA.

Events Industry Council - EIC. (2018). Economic Significance of Meetings to the US Economy.

Fratucci, A., Bantim, N., \& Melo, R. (2017). O Pronatec Turismo para além da empregabilidade: percepções na cidade do Rio de Janeiro-RJ (Brasil). Revista Turismo \& Desenvolvimento, (27), 153-155. 
Giosa, L. A. (1997). Terceirização: uma abordagem estratégica. Cengage Learning Editores.

Gonsalves, V. O. (2001). Terceirização; Trabalho Temporário; Orientação ao Tomador de Serviços, Brasília: MTE, SIT.

Guimarães, R. C. V. (2015). Trabalho Informal e Grandes Eventos na Periferia do Capitalismo. Khóra: Revista Transdisciplinar, 2(2).

Harvey, D. (1998). Condição Pós-Moderna: Uma pesquisa sobre as origens da mudança cultural. (7a. ed.). São Paulo: Edições Loyola.

Harvey, D. (2005). A Produção Capitalista do Espaço. São Paulo: Annablume.

Instituto de Pesquisa Econômica Aplicada-IPEA. (2018). Recuperado de https://www.ipea.gov.br/portal/index.php?option=com_alphacontent\&section=30\&category= 410\&Itemid $=352$

Jost, R., Fernandes, B., \& Soboll, L. A. (2014). A subjetividade do trabalhador nos diferentes modelos de gestão. In Soboll, L. A., \& Ferraz, D. L. S. Gestão de Pessoas: Armadilhas da organização do trabalho. São Paulo: Atlas

Kotler, P. (1998). Administração de empresas de serviços e serviços de apoio ao produto. In Kotler, P. Administração de Markenting-Análise, Planejamento, Implementação e Controle, 5, 411-429.

Lei $n^{o} 13.429$, de 31 de março de 2017. (2017). Altera dispositivos da Lei n o 6.019, de 3 de janeiro de 1974, que dispõe sobre o trabalho temporário nas empresas urbanas e dá outras providências; e dispõe sobre as relações de trabalho na empresa de prestação de serviços a terceiros. Brasília, DF. Recuperado de http://www.planalto.gov.br/ccivil_03/_ato20152018/2017/lei/L13429.htm\#: :text=Altera\%20dispositivos\%20da\%20Lei\%20n,presta\%C3\% A7\%C3\%A3o\%20de\%20servi\%C3\%A7os\%20a\%20terceiros.

Lei $n^{\circ}$ 6.019, de 3 de janeiro de 1974. (1974). Dispõe sobre o Trabalho Temporário nas Empresas Urbanas, e dá outras Providências. Brasília, DF. Recuperado de http://www.planalto.gov.br/ccivil_03/leis/L6019compilado.htm\#: :text=LEI\%20No\%206.019 \%2C\%20DE\%203\%20DE\%20JANEIRO\%20DE\%201974.\&text=Disp\%C3\%B5e\%20sobre $\% 20 \mathrm{o} \% 20 \mathrm{Trabalho} \% 20 \mathrm{Tempor} \% \mathrm{C} 3 \% \mathrm{~A} 1$ rio,Urbanas $\% 2 \mathrm{C} \% 20 \mathrm{e} \% 20 \mathrm{~d} \% \mathrm{C} 3 \% \mathrm{~A} 1 \% 20 \mathrm{outras} \%$ 20Provid\%C3\%AAncias.\&text=Art.,Consolida\%C3\%A7\%C3\%A3o\%20da\%20Leis\%20do\% 20Trabalho.

Lima, T. B., \& Amaral, E. V. S. (2018). A percepção dos colaboradores de um hotel da capital paraibana sobre a política de recrutamento e seleção. Revista de Turismo Contemporâneo, 6(1).

Maio, I. P. (2006). Antropologia e Turismo - reflexões teóricas sobre o estudo de processos socioculturaos nas localidades receptoras. Anais do IV SeminTUR - Seminário de Pesquisa em Turismo do MERCOSUL - UCS - Mestrado em Turismo, Caxias do Sul, RS, Brasil.

Martoni, R. M., \& Alves, K. S. (2019). As condições da classe trabalhadora em atividades características do turismo: especificidades e tendências socioprodutivas. Rosa dos Ventos Turismo e Hospitalidade, 11(1), 211-223. 
Meliani, P. F., \& Gomes, E. T. A. (2010). Contradições entre a importância do trabalhador e a precarização das relações de trabalho no turismo: notas primeiras de uma pesquisa de tese para doutoramento. Revista Turismo \& Desenvolvimento, 1(3/14), 117-126.

Minayo, M. C. S. (Org.). (1999). Pesquisa social: teoria, método e criatividade. Petrópolis: Vozes.

Oltramari, A. P., Paula, M. J. M., \& Ferraz, D. L. S. (2014). Do Departamento Pessoal ao Recursos Humanos Estratégico: os subsistemas e a sofisticação do controle do trabalhador. In Soboll, L. A., \& Ferraz, D. L. S. Gestão de Pessoas: Armadilhas da organização do trabalho. São Paulo: Atlas.

Oliveira, M. F. S., \& Oliveira, O. J. R. (2005). Carnaval, turismo e trabalho informal na Bahia: tanto negócio e tanto negociante. IVT, Caderno Virtual do Turismo.

Oliveira, C. (2007). Contratação de trabalho temporário na área de eventos - vantagens $e$ desvantagens. Trabalho de Conclusão de Curso, Brasília, DF, Brasil.

Petrin, N. (2015). Terceirização. Recuperado em 14, janeiro, 2002, de https://www.estudopratico.com.br/terceirizacao/

Pimentel, T. D., \& Paula, S. C. (2014). A inserção profissional no mercado de trabalho face às habilidades adquiridas na formação superior em turismo. Revista de Turismo Contemporâneo, 2(1).

Pinto, R. S. (2004). Trabalho temporário: uma contribuição para a compreensão dos direitos do trabalhador diante do paradigma da flexibilização. Cadernos Estudos Jurídicos, 7(7), 1194.

Relatório Programa Educação Para Todos no Brasil. (2014). Relatório Educação para todos no Brasil 2000-2015. Recuperado de

http://portal.mec.gov.br/index.php?option=com_docman\&view=download\&alias=15774-eptrelatorio-06062014\&Itemid=30192

Souza, D. (2016). O trabalho no turismo como temática nos periódicos científicos associados aos programas Stricto Sensu em Turismo no Brasil. Turismo e Sociedade, 9(1).

Stair, R. M., \& Reynolds, G. W. (2006). Princípios de Sistemas de Informação - Uma abordagem gerencial. São Paulo: Thonsom.

Teberga, A. (2020). Trabalho precário em eventos: precisamos falar sobre isso! Recuperado em 04, outubro, 2020, de https://www.labormovens.com/post/trabalho-prec\%C3\%A1rio-emeventos-precisamos-falar-sobre-isso

Tomazzoni, E. Educação Profissional em Turismo. (2007). Cria-se Mercadopela Formação? Revista Turismo em Análise, São Paulo, 18(2), 197-219.

Trigo, L. G. G. (2001). Turismo e civilização: mergulhando nos berços da humanidade. São Paulo: Contexto.

União Brasileira dos Promotores de Feiras - UBRAPE. (2019). Impactos e resultados dos eventos com foco em geração de negócios no Estado de São Paulo. Recuperado em 02, outubro, 2020, de https://ubrafe.org.br/download/ubrafeimpactoeventosfinal.pdf 
Vieira, V. A. (2002). As tipologias, variações e características das empresas de marketing. Rev. FAE, 5(1), 61-70.

FORMATO PARA CITAÇÃO DESTE ARTIGO

SILVA, M. O., BANTIM, N., \& COSTA, M. A. M. (2021). Precarização do trabalho no setor de eventos: um estudo inicial sobre os impactos para os trabalhadores e empresas. Revista de Turismo Contemporâneo, 9(1), 1-23. https://doi.org/10.21680/2357-8211.2021v9n1ID21645 